\title{
Study of XRD, FT-IR and Nonlinear Optical Properties of Doped and Undoped Barium Iodate Crystals Grown in Silica Gel
}

\author{
Sharda Shitole
}

\begin{abstract}
Single crystals of barium iodate were grown by simple gel technique by single diffusion method. By varying various parameters, optimum conditions for the growth were established. Crystals having different morphologies and habits were obtained. Prismatic, prismatic pyramidal, dendritic crystals were obtained. Some of them were transparent, some were transluscent, and few others were opaque. The crystals were doped by impurities such as $\mathrm{Fe}^{3+}$ and $\mathrm{Cu}^{2+}$. The formation of the compound was verified by $X$-ray diffractograms. The results were compared with the standard values given in JCPDS file. It confirms that the grown crystals are barium iodate, monohydrate. Structural analysis was carried out using FT-IR technique. It confirms the iodate group of the grown crystals. Nonlinear optical properties were studied by using powder second harmonic generation method. Effect of doping of $\mathrm{Fe}^{3+}$ and $\mathrm{Cu}^{2+}$ on the structure and nonlinear optical properties of bulk crystals was studied. Doping has no effect on the structure. Doping of $\mathrm{Cu}^{+2}$ inhibits nonlinear behavior of the substance, while $\mathrm{Fe}^{+3}$ doping of has less negative effect.
\end{abstract}

Index Terms-Barium iodate; silica gel, doping, XRD, FT-IR, NLO properties, SHG measurements.

\section{INTRODUCTION}

Most of the solid-state investigations are made by using well-developed crystals. Due to lack of natural crystals or their non-availability in purified form, the growth of reasonably bigger crystals of greater purity and homogeneity has long been exercised the minds of research workers.

Importance of gel growth can be visualized by the fact that number of researchers have grown and are growing crystals of technological potential by this method at minimum cost. Growth of crystals by gel method is a promising technique for growing single crystals of substances, which are sparingly soluble in water and decompose before their melting point. The technique is quite interesting as it could be used to grow ionic, organic and metallic crystals at ambient temperature. Suppression of convection currents and control of nucleation are the two principal functions of the gel, which leads to the practical utility of the method [1]. Moreover, the method is simple and inexpensive [2-5].

Single crystals of barium iodate, monohydrate $\left[\mathrm{Ba}\left(\mathrm{IO}_{3}\right)_{2}\right.$, $\mathrm{H}_{2} \mathrm{O}$ ] which exhibit prominent nonlinear optical property [6], were grown by gel method. Since the compound decomposes before its melting point, conventional high temperature

Manuscript received March 7, 2012; revised April 24, 2012

Sharda Shitole is with the Department of Electronics, Z. B. patil College, Dhule 424 002, India (e-mail: sjshitole @ hotmail.com, Tel: + 912562223414 , fax: +912562220678). methods for its growth are not applicable [7, 8]. These crystals were also doped with impurities such as $\mathrm{Fe}^{3+}$ and $\mathrm{Cu}^{2+}$. Dopants were incorporated to study their effect on properties of the grown crystals.

\section{EXPERIMENTAL}

The chemical reaction method is used to grow these crystals. The technique involves growing of single crystals by allowing the reaction of two solutions of soluble salts by diffusion through a gel with subsequent nucleation and the crystal growth, which continues due to the gradual precipitation of insoluble product. AR grade chemicals used for the growth of the crystals are $\mathrm{Na}_{2} \mathrm{SiO}_{3}, \mathrm{CH}_{3} \mathrm{COOH}, \mathrm{BaCl}_{2}$, $\mathrm{Ba}\left(\mathrm{NO}_{3}\right)_{2}, \mathrm{NaIO}_{3}, \mathrm{KIO}_{3}, \mathrm{FeCl}_{3}$, and $\mathrm{CuCl}_{2}$.

The chemical reactions inside the gel can be expressed as $X \mathrm{Cl}_{2}+2 \mathrm{YIO}_{3} \rightarrow X\left(\mathrm{IO}_{3}\right)_{2}+2 \mathrm{YCl}$,

Or $X\left(\mathrm{NO}_{3}\right)_{2}+2 \mathrm{YIO}_{3} \rightarrow X\left(\mathrm{IO}_{3}\right)_{2}+2 Y\left(\mathrm{NO}_{3}\right)_{2}$, where $X=\mathrm{Ba}$ and $Y=\mathrm{K}$ or Na.

To study the effect of dopants on structural and nonlinear optical properties, an attempt has been made to include impurities during the growth of the crystals. Dopant solutions (either $\mathrm{FeCl}_{3}$ or $\mathrm{CuCl}_{2}$ ) having different concentrations and different amounts were either incorporated in gel or in supernatant. With the development of electronic devices, much attention has been paid towards the role of foreign particles as impurities in the crystallization process, particularly in semiconductor industries [9] and in industrial crystallization [10]. By doping, it is possible to grow crystals as per requirement and of specific physical properties. Many scientists have already reported the enrichment effect of dopants on crystals [11]. Colour of the colored crystals is due to the inclusion of small amount of impurities [12].

\section{RESUlTS AND DISCUSSION}

Growth of more perfect crystals occurs away from the gel interface, since the rate of diffusion of the feed solution becomes less and then steady. In the steady state of concentration gradient, growth rate becomes steady which favors well developed crystals. In that case, well developed prismatic $\left(2 \times 2 \times 1.5 \mathrm{~mm}^{3}\right)$, prismatic pyramidal $(3 \times 2 \times 2$ $\mathrm{mm}^{3}$ ) crystals are obtained. Very slow rate of growth along one direction results in the platy crystals. Fast growth rate in one particular direction leads to the formation of elongated crystals like dendrites. Dendritic growth (10 to $\left.20 \times 1 \mathrm{~mm}^{2}\right)$ of barium iodate crystals occurs near the gel interface. It means that opaque dendrites are found to grow in the region of high concentration gradient when the growth rate is very 
high. Rate of arrival of the solute at the crystal surface influences perfection of crystal.

Different parameters such as concentration of reactants, $\mathrm{pH}$ of gel, impurities in the solvent, gel setting time, gel aging time, etc. have considerable effect on growth rate. Concentration of doping has no significant effect on the morphology of crystals.

\section{CHARACTERIZATION}

Doped and undoped crystals of barium iodate were characterized by XRD, FT-IR. Nonlinear optical properties were studied using SHG measurements.

\section{A. X-Ray Diffraction}

The X-ray diffractograms of gel grown undoped and doped barium iodate crystals were recorded using Miniflex model, Rigaku, Japan, X-ray diffractometer having wavelength $(\lambda)$ of $\mathrm{CuK} \alpha$ radiation $=1.5418 \mathrm{~A}^{0}$.

The diffractograms manifest that impurities have been accepted only in certain planes, but crystal structure remains unaffected. However, small change in lattice parameters is observed. Change in volume of unit cell is also observed. Volume of unit cell of doped crystals is slightly greater than undoped one. Volume of $\mathrm{Cu}$-doped unit cell is more than Fe-doped unit cell. This increase in volume may be attributed to ionic radii of doped impurities. The ionic radius of $\mathrm{Ba}^{+2}=$ $1.35 \mathrm{~A}^{0}, \mathrm{Cu}^{+2}=0.73 \mathrm{~A}^{0}$, and $\mathrm{Fe}^{+3}=0.645 \mathrm{~A}^{0}$. Thus, ionic radius of $\mathrm{Cu}^{+2}$ is more than that of $\mathrm{Fe}^{+3}$ and that both of these are less than $\mathrm{Ba}^{+2}$. This analysis shows that the crystal structure is monoclinic with $\mathrm{a} \neq \mathrm{b} \neq \mathrm{c}$ and $\alpha=\gamma=90^{\circ} \neq \beta$. The calculated values of $a, b, c$, and $\beta$ are in good agreement with the reported values [13]. The calculated values of lattice parameters of undoped and doped crystals, and corresponding reported values are represented in Table 1.

TABLE I: LATTICE PARAMETERS OF BARIUM IODATE, MONOHYDRATE

\begin{tabular}{ccccc}
\hline \multirow{2}{*}{ Lattice parameters } & \multicolumn{2}{c}{ Undoped } & \multirow{2}{*}{ Cu-doped (observed) } & Fe-doped (observed) \\
\cline { 2 - 3 } & Reported & observed & & $9.057(3)$ \\
$\mathbf{a ~} \mathbf{A}^{\mathbf{0}}$ & 9.061 & $9.014(7)$ & $9.076(4)$ & $8.007(5)$ \\
$\mathbf{b} \mathbf{A}^{\mathbf{0}}$ & 7.988 & $8.017(1)$ & $8.036(8)$ & $9.950(4)$ \\
$\mathbf{c ~} \mathbf{A}^{\mathbf{0}}$ & 9.918 & $9.932(4)$ & $9.918(9)$ & 90.00 \\
$\boldsymbol{\beta}^{\mathbf{0}}$ & 92.10 & 91.00 & 92.00 & 721.453 \\
$\mathbf{V}\left(\mathbf{A}^{\mathbf{0}} \mathbf{3}^{\mathbf{3}}\right.$ & 717.375 & 717.495 & 722.743 & 720 \\
\hline
\end{tabular}

\section{B. FT-IR Spectral Analysis}

The FT-IR spectra of undoped and doped barium iodate crystals were scanned by using FT-IR spectrophotometer, Spectrum - 2000, Perkin - Elmer model by placing sample $\mathrm{KBr}$ pellet in the sample beam in two ranges, $300-710 \mathrm{~cm}^{-1}$ and $400-4000 \mathrm{~cm}^{-1}$. Fundamental frequencies of the pyramidal iodate ions as have been reported earlier by

Nassau et al [14], Dasent and Waddington [15], Balicheva and Petrova [16], Sanyal and Nag [17], and Nyquist and Kagal [18] are in good agreement with the observed values. Table 2 represents the vibrational frequencies for the undoped and doped barium iodate crystals.

TABLE II: VIBRATIONAL INFRARED FREQUENCIES OF UNDOPED, CU-DOPED, AND FE-DOPED BARIUM IODATE CRYSTALS

\begin{tabular}{|c|c|c|c|}
\hline Fundamental frequencies & $\begin{array}{c}\text { Undoped } \\
\left(\mathrm{cm}^{-1}\right)\end{array}$ & $\begin{array}{c}\text { Cu-doped } \\
\left(\mathrm{cm}^{-1}\right)\end{array}$ & $\begin{array}{c}\text { Fe-doped } \\
\left(\mathrm{cm}^{-1}\right)\end{array}$ \\
\hline symmetric stretching frequency, $\gamma_{1}$ & 760.48 & 755.55 & 757.56 \\
\hline symmetric bending frequency, $\gamma_{2}$ & 382.05 & 382.79 & 382.86 \\
\hline asymmetric stretching frequency, $\gamma_{3}$ & 810.0 & 810.0 & 810.0 \\
\hline asymmetric bending frequency, $\gamma_{4}$ & 322.22 & 324.18 & 317.39 \\
\hline
\end{tabular}

\section{Powder SHG Measurements}

The selection of an efficient nonlinear material for growing a crystal among the wide varieties of available substances presents a problem. The search for new material has identified novel organic and inorganic systems of considerable potential and high performance [19]. Since the growth of single crystal of good optical quality is in most cases a long and difficult process. To overcome all these difficulties and to select the material for crystal growth, Powder second harmonic generation method was introduced by Kurtz and Perry [20]. It is valuable technique for rapid screening of potential second harmonic generating materials. It allows rapid evaluation of nonlinear optical property of the material under study in a form, which can be readily available in most of the cases. It gives an estimate magnitude of the effective nonlinear coefficient and gives information on phase matching condition for second harmonic generation..

In this technique, material in the powder form is irradiated with the intense laser beam and its second harmonic signal is compared with a known reference such as KDP powder.

Results of nonlinear coefficients represented in Table 3 indicate that barium iodate crystals are having nonlinear optic property, though its value of $d$ is comparatively smaller than that of KDP. $\mathrm{Cu}$-doping reduces nonlinear optic property significantly, while $\mathrm{Fe}$-doping also has negative effect but less than $\mathrm{Cu}$-doping. In brief,

\footnotetext{
$d_{\text {barium iodate }}>d_{\text {Fe-doped barium iodate }}>d_{\text {Cu-doped barium iodate }}$
} 
TABLE III: NONLINEAR COEFFICIENTS OF KDP, UNDOPED, CU-DOPED, AND FE-DOPED BARIUM IODATE CRYSTALS

\begin{tabular}{cc}
\hline Substance & Nonlinear coefficient $(\mathbf{d}$ 's) $\mathbf{~ p m} / \mathbf{v}$ \\
\hline KDP & 0.44 \\
Undoped barium iodate & 0.1935 \\
Cu-doped barium iodate & 0.05602 \\
Fe-doped barium iodate & 0.1362 \\
\hline
\end{tabular}

\section{CONCLUSIONS}

The following conclusions can be drawn from the above discussion.

- Gel technique can be successfully employed for the growth of barium iodate, monohydrate crystals.

- Doping of impurities has no significant effect on morphology of crystals.

- X-ray diffraction studies suggest that the grown crystals are barium iodate, monohydrate indeed. The calculated unit cell parameters and $\mathrm{d}$ values are in good agreement with the standard JCPDS data. There is a slight change in unit cell parameters due to doping but the overall structure remains unaffected. It has been observed that volume of unit cell increases in order of ionic radii of the dopant.

- Fundamental infrared frequencies, observed in all iodate compounds in general, are also found in FT-IR analysis in present investigation, which confirms the iodate group of the grown crystals. Doping has no effect on the structure.

- Powder second harmonic generation technique has proved the nonlinear nature of the substance. Value of nonlinear coefficient is determined. Doping of $\mathrm{Cu}^{+2}$ inhibits nonlinear behavior of the substance, while $\mathrm{Fe}^{+3}$ doping of has less negative effect.

\section{REFERENCES}

[1] A. F. Armington and J. J. O'Connor, "Gel growth of cuprous halide crystals," J. Cryst. Growth. 1968, vol. 3, no. 4, pp. 367-371.

[2] S. J. Shitole and K. B. Saraf, "Growth and study of some gel grown group II single crystals of iodate," Bull. Mater. Sci. 2001, vol. 24, no. 5, pp. 461-468.
[3] S. J. Shitole and K. B. Saraf, "Growth, Structural and microtopographical studies of calcium Iodate, monohydrate crystals grown by silica gel," Cryst. Res. Technol. 2002, vol. 37, no. 5, pp. 440-445.

[4] S. J. Shitole and K. B. Saraf, "Spherulitic growth of cadmium iodate in silica gel and its XRD and FTIR analysis," J. Adv. Sci. And Tech. 2007, vol. 10 , no. I \& II, pp. 42-55.

[5] M. S. Joshi and S. G. Trivedi, "Growth of single crystals of barium iodate and strontium iodate in silica gels," Cryst. Res. Technol. 1981, vol. 16, no. 1, pp. 19-26.

[6] B. Morosin, J. G. Bergman, and G. R. Crane, "Crystal structure, linear and nonlinear optical properties of $\mathrm{Ca}$ (IO3)2.6H2O," Acta. Crysta. 1973, vol. B29, pp. 1067-1072.

[7] S. L. Garud, N. K. Mahajan, and K. B. Saraf, "Study of gel grown mixed crystals of $\mathrm{BaxCa}(1-\mathrm{x})(\mathrm{IO} 3) 4$," Bull. Mater. Sci. 2009, vol. 32, no. 2, pp. 187-192.

[8] S. L. Garud and K. B. Saraf, "Growth and study of mixed crystals of Ca-Cd iodate," Bull. Mater. Sci. 2008, vol. 31, no. 4, pp. 639-643.

[9] A. J. R. De Kock, "In: S. P. Kelkar, et al (eds.)," Handbook of Semiconductors. North; vol. 8, no. 297, 1980.

[10] J. Nyrit. Industrial Crystallization. Elesevier, 1982.

[11] J. Dennis and H. K. Henisch. J. Electrochem. Soc. 1967, vol. 114, no. 263.

[12] H. C. Dake. Quartz family minerals: A handbook for the mineral collector. Whittlesey House, 1938.

[13] JCPDS Card for X-ray Diffraction Data No. 26 - 1405.

[14] K. Nassau, J. W. Shiever, and B. E. Prescot, "Transition metal iodates. I. Preparation and characterization of the 3d iodates," J. Solid State Chem. 1973, vol. 7, pp. 186-204

[15] W. E. Dasent and T. C. Waddington, "Iodine-Oxygen Compounds," Part I. Infrared Spectra and Structure of Iodates J. Chem. Soc. 1960, pp. $2429-2432$

[16] T. G. Balicheva and V. A Petrova, "Vibrational spectra of the IO3-ion in alkali iodates," J. Structural Chem. 1973, vol. 14, no. 3, pp. 424-430.

[17] G. S. Sanyal and K. Nag, "Thermal studies on the dimesoperiodates and iodates of $\mathrm{Ca}(\mathrm{II}), \mathrm{Sr}(\mathrm{II})$ and $\mathrm{Ba}(\mathrm{II})$ preparation and characterization of hexavalent iodates," J. Inorg. Chem. 1977, vol. 39, pp. 1127-1130.

[18] R. A. Nyquist and R. D. Kagal. Infrared Spectra of Inorganic Compounds. Academic Press, 1971.

[19] D. S. Chemla and J. Zyss. Nonlinear Optical Properties of Organic Molecules and Crystals. Academic Press; 1987.

[20] S. K. Kurtz and T. T. Perry, "A powder technique for the evaluation of nonlinear optical materials," J. Appl. Phys. 1968, vol. 39, no. 8, pp. 3798-3813. 